\title{
Erratum to: An empirical index of insulin sensitivity from short IVGTT: validation against the minimal model and glucose clamp indices in patients with different clinical characteristics
}

\author{
A. Tura $\cdot$ S. Sbrignadello $~ E$ E. Succurro $・$ L. Groop • \\ G. Sesti • G. Pacini
}

Published online: 7 April 2010

(C) Springer-Verlag 2010

\section{Erratum to: Diabetologia}

DOI 10.1007/s00125-009-1547-9

Unfortunately the $\alpha$ constant used in the $\mathrm{CS}_{\mathrm{I}}$ equation was incorrectly stated in the Methods and Discussion sections as being 0.276 , whereas it should have read 0.604 . The correct $\alpha$ constant was used in all calculations, and so this mistake does not affect any of the results in the paper.

The online version of the original article can be found at http://dx.doi. org/10.1007/s00125-009-1547-9.

\footnotetext{
A. Tura $\cdot$ S. Sbrignadello $\cdot$ G. Pacini $(\bowtie)$

Metabolic Unit, ISIB-CNR,

Corso Stati Uniti, 4,

35127 Padova, Italy

e-mail: giovanni.pacini@isib.cnr.it

E. Succurro $\cdot$ G. Sesti

Department of Experimental and Clinical Medicine,

University Magna Græcia of Catanzaro,

Catanzaro, Italy

L. Groop

Lund University Diabetes Centre, Lund University,

Malmö, Sweden

L. Groop

Research Program for Molecular Medicine, Helsinki University,

Helsinki, Finland
} 